\title{
Coulisses
}

Revue de théâtre

\section{Le Chemin des Petites Abymes}

ou Sans amour on est rien du tout (Inédit, 1999)

\section{Michèle Montantin}

\section{(2) OpenEdition}

\section{Journals}

Édition électronique

URL : https://journals.openedition.org/coulisses/499

DOI : 10.4000/coulisses.499

ISSN : 2546-9460

Éditeur

Presses universitaires de Franche-Comté

\section{Édition imprimée}

Date de publication : 31 décembre 2011

Pagination : 139-190

ISBN : 978-2-84867-404-9

ISSN : $1150-594 \mathrm{X}$

Référence électronique

Michèle Montantin, «Le Chemin des Petites Abymes », Coulisses [En ligne], 43 | Automne 2011, mis en ligne le 30 novembre 2016, consulté le 29 décembre 2022. URL : http://journals.openedition.org/ coulisses/499; DOI : https://doi.org/10.4000/coulisses.499 


\section{Le Chemin des Petites Abymes}

ou Sans amour on est rien du tout (Inédit, 1999)

\section{Michèle Montantin}

\section{RÉFÉRENCE}

Michèle Montantin, Le Chemin des Petites Abymes ou Sans amour on est rien du tout, 1999, Inédit

Création en 1999 au Centre Dramatique Régional de la Martinique, Théâtre Municipal de Fort de France. Mise en scène de Michèle Cesaire

\section{Présentation}

\section{Personnages}

LA PETITE FILLE. Kilt, fendu sur le côté fermé par une barrette. Petit chapeau de feutre rond sur cheveux noirs raides coupés à la Jeanne d'Arc ou à la chinoise. « Exotique » pour les européens et totalement indéfinissable: chinoise, indienne, eurasienne, mulâtresse, n'importe quoi, qui, dans le monde des blancs, porte la marque de l'ailleurs... lèvres charnues « africaines ». Elle aura tous les âges...

LE PÈRE. Un grand mec noir lisse beau. Pardessus anthracite, écharpe blanche, gants de cuir blond doublés de soie.

LA MÈRE. Tailleur noir croisé élégant, cape courte sur les épaules, chapeau surmonté d'une plume noire sur cheveux blonds décolorés, chaussures comme après-guerre semelles compensées.

EUGÉNIE. Peau foncée, cheveux très longs, métisse de blanc et de nègre dont le mélange a donné quelque chose d'indien. Elle est menue, a de très grands yeux qu'elle plisse avec dédain. Sa robe est bleue à pois blancs, de coupe créole dite « à 
corps $»^{1}$ et met en valeur des seins ronds et hauts. Elle porte des bottines de cuir bleu outre-mer. Elle s'appuie sur une ombrelle de madras bleu. Elle possède aussi un éventail caché dans son châle et dont elle s'évente souvent. Maintien aristocratique et définitivement supérieur. Cheveux roulés en chignon. Elle pourra défaire cette chevelure très longue et la brosser sur son épaule droite. Tout en étant une vieille dame, elle a souvent un air de petite fille mélancolique.

MATHILDE. Elle est blanche. Elle est maquillée. Ses cheveux très noirs mi-longs, coiffés comme après guerre, remontés sur le front. Bijoux perles et or. Chaussures de cuir luisant, hauts talons. Robe moderne, blanche, de bonne coupe, découvre ses jambes, belles, et presque ses genoux. Bas fins. Air... très sûr d'elle. Quelque chose de dominateur et de voluptueux. Accent parisien orné d'expressions faubouriennes. Paraît 60 ans mais doit en voir 70 . Elle " promène » une capeline de paille d'Italie bleu foncé, ornée d'un ruban blanc. Elle est encore très coquette.

\section{La Musique}

J'ai descendu dans mon jardin sera chanté sans accompagnement. Le motif des huit premières notes pourra être réutilisé avec un son semblable à celui des petites machines à musique en fer blanc que l'on remontait avec une clef.

Le motif pourra être repris sur un phrasé léwoz². Deux chansons se feront entendre aux moments indiqués: «La Goualante du pauvre Jean », dans une version très réaliste, style chanteur des rues, et « Sûrement mon bonheur », vieille valse créole chantée par une femme.

Le tambour ka improvisera des rythmes à l'évocation des rêves de la petite fille.

\section{La pièce}

\section{Scène 1}

(Eugénie entre en scène côté jardin avec l'air de ne pas vouloir qu'on la rattrape.

Mathilde la suit de peu.

Eugénie accélère le pas comme pour la perdre.)

MATHILDE (Dans les coulisses.)

Eugénie, où vous êtes encore une fois? Oh la la...

EUGÉNIE

Ou vlé maché, pou maché ou ké maché3!! On va voir qui de toi ou de moi... est capable de soutenir un rythme de marche.

MATHILDE (Toujours dans les coulisses.)

Ma p'tite poulette, si tu crois m'semer... Tu t'goures!!

EUGÉNIE

En tout cas je te ferai transpirer... Ou ké vwè sa ou ké vwè̀ ${ }^{4} .$.

MATHILDE (Entrant sur scène essoufflée et suante.)

Si tu voulais m'tuer... il fallait l'faire... ya longtemps... Maintenant c'est trop tard... 
EUGÉNIE (Faisant semblant de ne pas l'entendre et poursuivant sa course trébuchante.)

J'ai descendu... dans mon jardin...

J'ai des...cendu... dans mon jardin...

Pour y cueillir... du romarin...

Pour y cueillir... du romarin...

Gentil coquelicot mesdames...

Gentil coquelicot nouveau...

MATHILDE

Ah je l'entends!... avec ses airs de grande dame ce n'est qu'une petite garce...!

EUGÉNIE (S'écroulant, à bout de souffle, s'assied à même le sol et s'évente avec force en chantant

d'une voix épuisée.)

J'ai... descendu... dans... mon jardin... J'ai... descendu... dans... mon jardin...

MATHILDE (L'apercevant ralentit sa course, s'avance chancelante et s'assied lourdement à ses

côtés en s'éventant elle aussi avec sa capeline.

C'était vraiment pas la peine tout c'cinéma pour en arriver là...

C'est plus d'mon âge, et encore moins du tien!!

EUGÉNIE

Nul ne vous a demandé de me suivre, encore moins moi...

"Gentil coquelicot mesdames, gentil coquelicot nouveau... »

MATHILDE

IH! IH! IH!: « Le jardin de ton père », on peut laisser passer, mais alors! « Ton coquelicot nouveau ",

Alors ça!

Où t'as vu pousser des coquelicots sur ton île à la noix!

EUGÉNIE

Je chante ce qu'il me plait, vous n'allez pas prétendre me dicter les paroles des chansons que je chante?

Et puis pourquoi adressez-vous la parole à une habitante d'une île à la noix? Personne ne vous a forcée à venir y habiter...

MATHILDE

Ça c'est vrai... Personne m'a forcée...

EUGÉNIE

Pourtant vous y êtes venue...

Je ne sais pas, moi, pourquoi... si vite après la guerre... on vous a vus débarquer vous et votre... quatrième futur mari...

MATHILDE

Pas le quatrième, le troisième...

EUGÉNIE

Troisième, si vous voulez... de toutes les manières, pour moi cela ne fait aucune différence. Dans mon milieu on se marie une fois et une seule!

MATHILDE

Ah! Oui? Mariée, vraiment mariée??... À moi on m'a dit qu'il ne t'avait pas épousée à l'église, rapport à ses convictions athées.

Il parait même que tu écrivais tous les mois au pape, Madame, pour qu'il bénisse ton union.

Malgré ça, tu as tout supporté en bonne catholique: ses maitresses... les enfants de ses maîtresses... Eh ben dis donc, quelle patience, Eugénie, quelle patience!! 
EUGÉNIE

Je vous interdis, Mathilde, de prendre avec moi cet air de pitié. Et puis... nous ne sommes pas ici pour parler de nous, de vos maris ou du mien, mais à cause... à cause de quoi?

Vous m'embrouillez les idées avec vos souvenirs...

Mais enfin, pourquoi nous a-t-on réveillées??

MATHILDE

C'est bizarre ce qui nous arrive. Je n'arrive pas non plus à me rappeler pourquoi je me suis réveillée...

EUGÉNIE

Je me le demande bien moi aussi...

MATHILDE

Je dormais... et dans ce sommeil je faisais un rêve...

EUGÉNIE

Moi aussi j'étais dans un rêve, je m'en souviens...

MATHILDE

Je revoyais cette vie d'avant... quand j'ai débarqué du Colombie, la foule qu'il y avait sur le quai!

Il était, c'est le cas de le dire, « noir » de monde!

Je débarque à la Pointe-à-Pitre, et me voilà entourée de gens tout noirs... quel étourdissement, quel dépaysement, quel déplacement...

EUGÉNIE

Arrêtez de prendre vos airs de surprise imbécile...

Vous aviez déjà vu des Noirs... non?!

Mon fils... le mari de votre fille... par exemple...

À Paris... avec tous les amis qu'ils avaient... vous aviez déjà pu apprécier, vous qui aimiez tant les hommes, comme ceux d'ici peuvent être intéressants...

Et puis cessez de jouer pour moi, je ne serai jamais bon public en ce qui vous concerne, vous semblez oublier que ma mère était noire et mon père blanc... Moi, je n'ai jamais trouvé étonnante la couleur des gens, par contre, le degré de bêtise qu'ils peuvent atteindre ne cesse de me surprendre...

MATHILDE

Prenez vos airs de grande dame, Eugénie, n'empêche que votre cervelle a l'air tout aussi ramollie que la mienne...

Dans quel sommeil étions-nous exactement plongées?

Et puis, je voudrais quand même bien me rappeler pourquoi ils ont cru bon nous faire à nouveau nous rencontrer sur ce morne...

D'ailleurs, vous, qui savez tout de cette île... Il s'agit bien du morne que l'on trouve quand on prend le chemin des petites Abymes, le morne... Udol, d'où l'on aperçoit l'hôpital et Baimbridge? Derrière la villa de ma fille...

EUGÉNIE

Derrière la villa de Mon fils et de votre fille.

MATHILDE

Ah oui, Votre fils... un des plus beaux nègres de Paris... intelligent, raffiné et sensible... les femmes l'aimaient... beaucoup... il le leur rendait bien... celui-là... on pourrait en dire qu'on n'dira pas... parce que l'on n'est pas de celles qui cherchent à semer la zizanie... mais il y en aurait beaucoup... beaucoup à raconter... 
EUGÉNIE

Vous savez Mathilde, mon éducation m'a toujours empêchée de vous le dire de notre vivant, mais en cet instant je vais passer outre: Mathilde je ne vous aime pas!

MATHILDE

Et c'est peu de le dire... Merci quand même pour ta franchise mais je le savais...

Ah ce chemin des Petites Abymes, voilà un nom qui m'a toujours fait rêver... Pas toi?

Parce que, les abymes, généralement c'est profond, insondable même.

Et là, dans cette île où je débarquais pour rejoindre ma fille, il fallait qu'elle habite aux Petites

Abymes.

Petites abymes du plaisir,

Première rides au coin du regard,

Premières flétrissures de l'amour.

Où habitez-vous?

Aux Petites Abymes chez ma fille et mon gendre... en attendant de trouver mieux...

Ouais, drôle de nom...

Je me souviens maintenant!

Brusquement, je n'étais plus dans mon rêve...

Je t'ai aperçue courant comme une vieille folle devant moi montant à toutes jambes le chemin des Petites Abymes...

Je me suis dit que tu allais voir les enfants et qu'il fallait que je sois là pour qu'ils n'oublient pas qu'ils sont aussi de mon sang...

J'ai couru derrière toi...

Tu as essayé de me semer. Et voilà...

Pourquoi tout ça?

(On entend une voix de petite fille.)

"J'ai descendu dans mon jardin

J'ai descendu dans mon jardin

Pour y cueillir du romarin

Gentil coquelicot mesdames

Gentil coquelicot nouveau »

EUGÉNIE

C'est elle! Elle est venue dans mon rêve...

MATHILDE

Ouais... c'est bien elle, la fille de ma fille, c'est elle tout craché, venir me trouver jusque dans mes rêves...

EUGÉNIE

Ce rêve était affreux: des hommes brûlaient tout vifs dans une pièce de cannes...

Des cavaliers montés sur des chevaux tournaient tout autour pour que personne n'échappe au brasier...

Ceux qui brûlaient paraissaient encore plus noirs que d'ordinaire... Seuls leurs yeux vivaient encore dans la grimace hideuse de leur face torturée... Il y avait une odeur... de poulet grillé.

À ce moment-là, j'ai vu ma petite fille... Elle se tenait devant moi et tendait le doigt vers le champ... elle ouvrait et fermait la bouche, ouvrait et fermait la bouche... 
MATHILDE

Ça pour ouvrir la bouche, ni ma fille ni ton fils n'ont su lui apprendre quand il fallait parler et quand il fallait se taire!

EUGÉNIE

Elle me criait quelque chose... et je voyais des larmes couler en abondance sur ses

joues... mais je n'entendais pas ses paroles... c'est cette vision qui m'a tirée en sursaut de mon sommeil...

MATHILDE

Ouais, tu as raison... c'est bien elle.

Elle était aussi dans mon rêve, elle ouvrait aussi la bouche... mais j'entendais très bien ce qu'elle me disait... avec son air supérieur:

(Imitant la petite fille et faisant sonner tous les « $p »$ )

«- C'est inutile, tu sais, d'éplucher les radis, c'est dans la peau que se trouvent toutes les vitamines... Chez le père de mon père, on n'épluche pas les radis! »...

EUGÉNIE

C'était la grande idée de mon époux, son grand-père: «Les vitamines sont dans la peau! »... Ils ont toujours eu une sorte de folie de l'imagination dans cette famille-là...

MATHILDE

Ça, pour avoir des idées, il n'en manquait pas, il en avait des tas, mais à part ça: rien dans les mains, rien dans les poches...

EUGÉNIE

Les terres que mon père m'avait données pour dot, il les avait offertes, au nom de la République, à la toute jeune commune Noire des Abymes... « Que la terre soit à ceux qui la travaillent! »... La plus riche terre à cannes du Morne-à-l'Eau...

MATHILDE

Un vrai communiste celui-là...

EUGÉNIE

Une terre noire, profonde, produit ancien du calcaire de bonites et de l'humus des forêts, l'eau en bas...

MATHILDE

Un vrai fou...

EUGÉNIE

Alors nous n'avions que ce que mes sœurs richement mariées...

MATHILDE

Et dont les maris n'avaient pas refusé, eux, la dot...

EUGÉNIE

... m'avaient offert...

N'exagérez pas Mathilde! En fait vous ne supportiez pas l'amitié de ma petite fille et de son grand-père, et comme elle ne vous a jamais aimée...

MATHILDE

Ça te ferait plaisir de croire ça, hein? Mais la vérité c'est que ma petite fille me ressemble beaucoup plus qu'à toi!

EUGÉNIE

Ah bon? Vraiment? Qu'est-ce qui vous fait dire ça?

MATHILDE

Ton mariage, ton histoire de pape, les maîtresses de ton mari, tout ça... Elle, elle aurait fait comme moi! 
EUGÉNIE

Quoi?

MATHILDE

Pfuit!! Partie, envolée...

(On entend de nouveau la voix de la petite fille.)

J'ai descendu dans mon jardin

Pour y cueillir du romarin

Gentil coquelicot mesdames

Gentil coquelicot nouveau

MATHILDE

Mais qu'est-ce qu'elle veut à la fin?...

EUGÉNIE

Mathilde vous n'avez pas changé... vous serez la même de toute éternité: tout, tout de suite... Enfin... Et bien, montons jusqu'au sommet du morne ${ }^{5}$, nous y verrons les choses d'un peu plus haut... mais inutile de me tenir la main si je trébuche ou de me souffler dans la figure si je suffoque... mon éventail et mon ombrelle feront très bien l'affaire...

(Elles s'éloignent l'une suivant l'autre.)

\section{Scène 2}
Le Décor
(La scène est le signe d'une rue qui coule comme un fleuve du côté jardin au côté cour, délimitée par un chemin de lumières chaudes: entrées des beuglants, des brasseries et des théâtres comme après la guerre rue de la Gaieté.
En fond de scène le ciel de Paris sur un écran où pourront également être projetés les champs de canne en flammes et la haute mer profonde couleur d'encre bleue.
Un petit pont en forme de croissant de lune franchit la rue en son milieu et peut s'élever dans les cintres en supportant une ou deux personnes.
La petite fille est assise au bord de la scène, les pieds balançant dans la salle, elle a l'air un peu fiévreux...
L'homme est debout côté cour, il fume des gitanes avec des gestes élégants et précis. La mère est côté jardin, seule la plume de son chapeau accroche la lumière.
Le père et la mère se déplaceront et viendront s'asseoir l'un sur le banc et l'autre sur le pont, se faisant presque face...
Eugénie et Mathilde descendront des cintres assises sur des balancelles.)

\section{LA PETITE FILLE}

(Chantant songeuse)

Je cherche après Ti-ti-ne

Ti-ti-ne ô Ti-ti-ne

je cherche après Ti-ti-ne

et je ne la trouve pas... Tu sais qui est Titine toi?

LE PÈRE

\section{LA PETITE FILLE}

Je savais que tu ne répondrais pas. Tu fais ça souvent... Tu écoutes... tu restes là l'air de quelqu'un qui cherche une réponse... ou l'air de quelqu'un qui, tout près de donner une réponse, doute qu'elle soit la bonne. 
LE PÈRE

Ah oui?

LA PETITE FILLE

Oui! c'est comme ça qu'tu fais...

(Chantant)

Je cherche après Ti-ti-ne,

Ti-ti-ne ô Ti-ti-ne

Je cherche après Ti-ti-ne

et je n' la trouve pas...

Moi je la vois tout à fait bien, Titine, une petite femme pressée... une midinette... une petite main, comme disait ma grand-mère du côté blanc: Elle passe vite en martelant le trottoir de ses chaussures un peu trop hautes, avec un déhanchement calculé pour se donner de l'assurance.

Je ne vois pas son visage puisqu'elle passe son temps à marcher vite dans la ville pour que l'autre qui cherche après elle, ne la trouve pas... Et elle fait bien attention à ne pas tourner la tête pour que si l'autre la suit, il ne la reconnaisse pas.

LE PÈRE

Et lui, celui qui cherche Titine?

LA PETITE FILLE

Ben c'est Panam, Monsieur Paris, quoi ! tu sais...:

(Chantant.)

Panam, Panam, Panam, je te suis en marchant derrière toi

Panam, Panam, Panam, tu me fais le coup du souviens-toi...

Panam, Panam Panam, lalalalallalalalallalalallalalla

La la la lalalalalalalalal la la lalalalalalallalalallalalll Panam!

C'est bien comme ça que la mère de ta femme appelait Paris... Elle en parlait sans arrêt de son Panam, et Panam ci et Panam là, et comment à Panam c'est bien mieux que chez nous, dans l'île..

Et bien Panam porte un imperméable gris, comme dans les films de gangsters, un feutre gris dont il rabat le bord et l'on ne voit pas son visage à lui non plus.

Monsieur Paris c'est lui, il court après Titine.

Tu me diras: Mais pourquoi Panam court-il après Titine ? Qu'est-ce qu'il lui veut ?

Et bien certainement pas des choses très belles, si Titine elle se cache comme ça et si elle court si vite sur ses talons trop hauts, c'est bien parce que ce Monsieur Paris ne lui veut pas du bien, pas vrai papa?

LE PÈRE

Tu as toujours de drôles d'idées... Paris... un homme !?

(Dans une jubilation intense.)

Paris c'est une ville! La ville la plus fantastique que je connaisse!

1935: La première fois que je suis descendu du train après avoir débarqué au Havre et que j'ai vu tout ça, je suis resté muet, étonné... je ne peux te dire le sentiment que j'éprouvais.

Paris, la ville Lumière! Et c'est vrai! Il y avait de la lumière partout. Je ne pensais pas qu'une telle chose soit possible: 
Tant de maisons,

Tant d'avenues,

Tant de rues,

Tant de librairies,

Tant d'autos, tant de gens,

Tant de femmes !

Mon île m'est alors apparue comme la province... de la province. Contrée malhabile et fermée sur elle-même, escargot enroulé sur son hélicoïde...

Paris! Ville heureuse où les Nègres comme moi, avec leurs frères d'Afrique et de Madagascar menaient la vie de zazous dans les bals nègres d'avant guerre.

LA PETITE FILLE

Et on ne vous détestait pas? On ne vous injuriait pas parce que vous étiez noirs? Vraiment?

LE PÈRE

Si certains haïssaient notre couleur, nous ne le voyions pas.

Nos maîtres nous tenaient en grande estime... des camarades français étudiants partageaient notre amitié et dansaient sur nos musiques. Les femmes nous aimaient et j'ai aimé Paris...

Je ne suis pas d'accord avec toi, Paris est une femme...

LA PETITE FILLE (Se dressant rageuse.)

Et moi, j'ai détesté cette ville, grise! Sale! Triste! Qui sentait encore la guerre!

Ah oui je la détestais!!!

Tous ces mendiants sous les ponts... Tous ces gens qui ont faim et froid... J'ai tellement peur de devenir comme eux... mais je n'ai pas pitié d'eux, non père, je n'ai pas pitié d'eux.

Je me suis guérie une fois pour toute de toute ma pitié,

Comme tu me l'as demandé,

Débarrassée une fois pour toute de peur de m'en déchirer le cœur.

(Avec la même jubilation que son père plus haut.)

La seule, la seule chose que j'aime: les chansons qui gueulent par toutes les portes battantes des bars et des brasseries jusque sur le trottoir où nous passons.

Chansons déchirées qui vous cognent là et vous laissent sans souffle!

LA VOIX D'UN HOMME QUI HURLE

« Demandez le Figaro, le Figaro, demandez le Figaro, dernière édition!!! »

LA PETITE FILLE

(Comme une litanie avec distance sinon froideur.)

Nous marchions sur le boulevard et l'homme venait vers nous traînant sa jambe de bois.

Son appel était si désespéré... il avait l'air de crier:

— «Ayez pitié de moi, ayez pitié de moi!»

- Papa achète lui son journal papa, je t'en prie! Tu vois bien comme il est malheureux, tu vois bien comme il souffre, tu vois bien sa jambe de bois! Tu vois bien que personne ne veut de son journal parce qu'il fait trop froid ce soir dans cette avenue, parce qu'il est trop seul et trop malheureux, et qu'il fait peur et qu'il fait mal...

LE PÈRE

(De même, l'air d'une leçon apprise souvent à lui même répétée.)

Il faut apprendre à résister, si tu te penches sur la souffrance des autres tu ne pourras 
pas survivre. Elle t'envahira, elle te fera mourir. Il faut te rendre imperméable, il faut savoir résister à la tentation de recevoir cette souffrance, de la partager, si tu te laisses allée à cette faiblesse, ils finiront par t'avoir...

LA PETITE FILLE

J'essaie, j'essaie, papa, j'essaie de me rendre imperméable, mais je n'y arrive pas toujours.

LE PÈRE (Chuchotant.)

C'est comme les regards... as-tu remarqué les regards?

LA PETITE FILLE (De même.)

Je les vois et je les sens. Mais c'est vrai que déjà j'ai beaucoup progressé dans la technique de l'évitement.

LE PÈRE

$\mathrm{Ah} ! \mathrm{Tu}$ dis l'évitement...

LA PETITE FILLE

Tu ne peux pas savoir ce qui se passe en vérité.

Même quand je suis seule, même quand tu ne m'accompagnes pas, et que les gens se disent juste un peu que j'ai quelque chose de bizarre, dans les yeux, la bouche ou le regard, et bien j'évite de leur faire savoir que je sais qu'ils me regardent.

Je les frôle comme si je n'étais pas là

... Regarde comment je fais... (Elle a sauté sur le pont et y marche comme une équilibriste sur son fil.) Je marche avec une telle supériorité, je suis réellement à une telle hauteur, que je ne suis même pas là...

LE PÈRE (Se chantonnant à lui-même une chanson très ancienne dont il se souvient pas à pas.)

Je suis l'étranger...

Celui qui n'est pas d'ici...

Celui qui vient d'ailleurs...

Celui dont le nombril ne repose pas sous l'arbre de la cour...

Celui... qui sent les odeurs que vous ne sentez pas

Celui dont... vous sentez l'odeur différente

Celui qui... se sent différent.

LA PETITE FILLE

Non! Moi je ne me sens pas étrangère!

C'est ici qui est différent.

$\mathrm{Tu}$ as vu ces arbres si gris noirs et décharnés, sans feuilles?

LE PÈRE

Mais tu as aimé la neige ? Souviens-toi de la neige !

LA PETITE FILLE

Ah oui, la neige!

C'était à la pension Maintenon.

Nous étions dans le dortoir et une fille qui était à la fenêtre a dit :

«Venez voir! Venez voir la neige ! La neige elle tombe !!! »

Et toutes les filles se sont précipitées à la fenêtre.

Moi je respirais très fort l'odeur de neige, l'odeur de froid.

Nous sommes, toutes sorties, dans la cour, au pied des marronniers noirs,

la tête renversée en arrière, un goût de sang dans mes narines,

les yeux remplis de neige fondue tourbillon de douceur blanche

et même nos cris n'étaient plus aigus 
et tout m'étourdissait,

et j'oubliais à quel point je détestais ce pays et son hiver !...

LE PÈRE

L'hiver... il y a dans l'hiver un moment particulièrement propice à l'activité intellectuelle, et puis cela débouche sur quelque chose de tellement prodigieux... le printemps... ne me dis pas que tu n'aimes pas le printemps...

LA PETITE FILLE

Je haïssais l'été plus que l'hiver.

Je craignais toujours qu'il ne fasse pas beau.

Et, quand le soleil était enfin là, je savais la saison fragile, éphémère...

Je vivais les étés d'Europe avec la certitude de leur fin prochaine, une brûlure au cœur pareille à celle que le soleil causait à ma peau blanchie par leur hiver.

LE PÈRE

Ne me dis pas que tu n'aimes pas le printemps...

LA PETITE FILLE (Tout à fait excitée.)

Les marronniers qui paraissaient des êtres morts se mirent à bourgeonner !

A-t-on jamais vu quelque chose d'aussi extraordinaire que des bourgeons de marronniers?

Ça gonfle, pousse, grossit,

Ça se tend et brille comme une peau huilée et la gomme perle au bout,

Ça éclate! Ça laisse passer des petites feuilles qui se mettent à se déplier de plus en plus vite.

Cela s'ouvre... s'étend... du vert, du vert... j'en aurais mangé si j'avais pu !

LA MÈRE

C'est en automne que nous nous sommes rencontrés...

LA PETITE FILLE

Moi, c'est l'automne que je préférais... Je n'avais plus peur que l'été s'achève puisqu'il était déjà fini...

Il s'éternisait dans une mort très douce avec ses ors, ses rouges, ses bruns qui apaisaient ma brûlure.

Quand tout était fini, ne restait que la poussière de toutes les feuilles tombées et l'odeur mélancolique des feux qui me rappelaient les boucans ${ }^{6}$ de ton jardin.

LE PÈRE (Répondant à la mère.)

Je m'en souviens.

LA PETITE FILLE

Racontez moi, racontez-moi encore, j'aime tellement cette histoire...

LA MÈRE (Sortant de la semi pénombre où elle demeurait cachée.)

Ma meilleure amie sortait avec un étudiant antillais, elle s'appelait Olga Olszewska... très belle, très intelligente...

Un jour elle m'a conduite chez lui, André, c'était son prénom, il habitait une chambre minuscule sous les combles au quartier latin... le phonographe tournait... de la musique... des biguines ${ }^{7} .$. la fête quoi... et ton père est entré, il étudiait chez un de ses amis dont la chambre était voisine... il était venu demander que l'on fasse moins de bruit...

LA PETITE FILLE

Vraiment... c'était bien là la raison ?... 
LE PÈRE

Quand je l'ai vue, j'ai cru qu'elle était elle aussi une étrangère... c'est cela qui m'a donné l'audace...

LA MÈRE

Je revenais de vacances à la Baule, j'avais tellement bruni que j'en étais noire...

LE PÈRE

Je t'ai prise pour une Algérienne...

LA MÈRE

D’ailleurs tu m'as demandée si j'étais d'Afrique du Nord...

LE PÈRE

Tu m'as répondu: « Non, je suis parisienne... »

C'était très impressionnant...

LA MÈRE (Éclatant d'un rire sonore et triomphant.)

Oui, tu avais l'air bizarre, tu croyais que je me moquais de toi...

LA PETITE FILLE

Il était comment?

LA MÈRE

Beau, grand, fort, bien fait, avec un sourire lumineux et très doux...

LA PETITE FILLE

Vous êtes tout de suite tombés amoureux... le coup de foudre quoi !?

LA MÈRE

Le coup de foudre...

LA PETITE FILLE

C'était ton premier amour?

LA MÈRE

Mon premier important grand amour..

J'avais eu un premier amoureux, un coup de foudre quoi! Violent, fugace... Je l'ai rencontré aux pieds de la tour Eiffel... il était tchécoslovaque... de Prague... il visitait Paris... en quelques minutes j'étais dans ses bras, nous sommes montés à pied presque jusqu'en haut, et nous ne cessions de nous embrasser.

Ah! Comme nous nous sommes embrassés, tu ne l'imagines pas... je ne voyais plus rien, je n'entendais plus rien, je savais que Paris était là, la Seine, les boulevards, je savais que le monde était là, mais il n'existait pas, rien ne comptait que sa bouche et ses bras et nos baisers sans fin, sans fin, sans fin, sans fin...

LA PETITE FILLE

Et après...

LA MÈRE

Quoi?

LA PETITE FILLE

Et après... puisque ce n'est pas avec lui que tu m'as faite mais avec papa...

LA MÈRE

Oh! Rien... nous avons eu un rendez-vous... mais il ne s'est rien passé, nous étions redevenus des étrangers...

LA PETITE FILLE

Et avec papa, c'était comment?

LA MÈRE

Des promenades, tout Paris, du Nord au Sud et du Sud au Nord, des discussions à n'en 
plus finir...

Je travaillais à Montparnasse et lui était pion à Chaptal... alors nous nous croisions à Saint-Michel... mais moi sur un quai, lui sur l'autre, séparés par le chemin de rail. Nous nous adorions de loin, nous nous envoyions des baisers... Je ne pouvais imaginer la vie sans lui...

LA PETITE FILLE

Vraiment vous faisiez ça?

LE PÈRE

Et moi la vie sans elle...

LA PETITE FILLE

Et ta mère, elle ne disait rien?

Il était noir quand même... comment ça se passait avant-guerre à Paris avec les Noirs ?

LA MÈRE

Ah ! Ma mère ne l'aimait pas! Ma mère n'aimait pas les Noirs!

Mais je lui ai dit, «c'est lui que j'aime et si tu ne veux pas de lui, c'est lui que je choisis et tu ne me reverras pas! »... Alors elle a accepté...

LA PETITE FILLE

Et ton père?

LA MÈRE

À cette époque je n'avais pas encore fait sa connaissance. Il avait abandonné Bruxelles après le départ de ma mère, et l'avait suivie jusqu'à Paris... Nous ne nous étions jamais vus... Nous nous écrivions depuis deux ans, et justement, six mois après avoir rencontré ton père, je lui ai fixé rendez-vous dans un café du quartier latin.

Il devait avoir un journal à la main et moi un chapeau que je lui avais décrit. Il est venu s'asseoir, il a eu l'air surpris en me voyant. En fait nous prenions souvent la même ligne de métro, nous nous croisions, et il me dit d'ailleurs:

- «Ainsi c'est toi la Blanche qui sort avec ce Nègre... »

LA PETITE FILLE

C'est vrai il a dit ça!?

Et alors, ça t'a fait de la peine...

LA MÈRE

Oui...

LA PETITE FILLE

Et après...

LA MÈRE

Après j'ai dit à mon père que s'il voulait me revoir, comme j'aimais ce Noir, qu'il faudrait qu'il l'accepte pour me revoir moi... Il s'est fâché, on ne s'est plus revu ni parlé... quelques mois... et puis il a demandé à rencontrer ton père et ils sont devenus amis...

LA PETITE FILLE

Elles se sont rencontrées quelques fois, hein maman?

LA MÈRE

Qui donc?

LA PETITE FILLE

Ma grand-mère noire et ma grand-mère blanche: Eugénie et Mathilde.

LA MÈRE

Oh! Oui, quelques fois. Elles ne s'aimaient pas vraiment. 
LA PETITE FILLE

Pourquoi?

LA MÈRE

Pas la même éducation, pas la même vie.

Ta grand-mère Eugénie avait reçu une éducation classiquement bourgeoise très catholique et très « bien pensante ».

Ta grand-mère Mathilde était une femme moderne. Elle prétendait ne se laisser faire par rien et par personne et avait décidé de survivre à tout et contre tous.

LA PETITE FILLE

Et grand-père, le père de papa?

LA MÈRE

Ah! Lui, je l'aimais vraiment bien... Quand je suis arrivée à la rue Schoelcher où se tenait sa petite maison, je n'oublierai jamais son grand sourire d'accueil...

LA PETITE FILLE (Chantonnant.)

Chinoise verte, baguettes de tambour!

Chinoise verte, baguettes de tambour!

À la communale mes petits camarades m'appelaient Chinoise verte à cause, disaient-ils, de la couleur de ma peau.

Moi je ne la trouvais pas verte ma peau!

Ils tournaient autour de moi dans la cour de récréation en se tenant par la main et criaient à tue-tête :

«Chinoise verte

Baguettes de tambour!

Chinoise verte! Baguettes de tambour»

À cause de mes cheveux raides, raides, tu sais...

Je leur dis :

— « je ne suis pas chinoise » je suis antillaise.

Elles ne savaient même pas où c'était

- Je leur dis : Mais oui: l'Amérique est là, et bien mon île est là, dans la Caraïbe.

Alors elles croyaient que je leur parlais de l'Afrique, où d'après elles, vivaient les nègres cannibales!

Alors quand je leur ai dit qu'il n'y avait dans mon île ni serpents venimeux, ni lions, ni cannibales, elles refusèrent de me croire!

Mais j'ai lu tant de déception dans leurs yeux, maman, que j'ai raconté des histoires:

" Je viens d'un pays où vivent les éléphants qui trompent énormément,

Les tigres griffus,

Les panthères noires, comme les habitants,

Les hippopotames aux narines impudiques,

Les zèbres à rayures!

Bien entendu, tout le monde est cannibale !!

Nous adorons manger de la chair humaine.

Dans ma tribu à moi, nous dévorons ceux que nous capturons dans les tribus voisines... et... vous savez le morceau du corps humain que je préfère?»

(Imitant les petites camarades.)

- Non, nous ne savons pas! Quel morceau ? Dis-le nous, dis-le nous!

- Je ne peux pas vous le dire! 
- Si ! Dis le nous, ô je t'en prie, dis-le nous!

- Eh bien! (Chuchotant.) ce sont les oreilles, c'est é-las-tique comme du schweem-gum ! Je mâche longuement, très longuement les oreilles de mes ennemis...

AH AH!!

LA MÈRE

Tu exagères !!

LA PETITE FILLE (Très froide.)

Mais non maman, je n'exagère pas.

D'ailleurs c'est toi qui exagères avec ton air d'être toujours passée au travers des gouttes d'eau!

LA MÈRE

La vie t'apprendra...

EUGÉNIE (Elle est descendue tout doucement des cintres sur sa balançoire qui se stabilise 1 mètre 50 au dessus du plateau.)

La vie n'apprend rien qu'on ne sache déjà, intimement: on sait l'amour, on sait la mort, on sait les blessures quand elles vous arrivent, on reconnaît le goût des larmes... On joue seulement à ne pas savoir pour ne pas avoir trop peur...

LA MÈRE

C'est ta grand-mère, mère de ton père, qui me disait souvent: « La vie nous lave et nous relave dans l'eau de toutes peines si bien que nous rétrécissons et que la mort nous trouve plus désarmés que l'enfant qui vient de naître. »

LA PETITE FILLE

Je n'aime pas que tu parles de la mort!

Pourquoi tu parles tout le temps de la mort?

LA MÈRE (Prenant le père à témoin.)

Moi ? Tu trouves vraiment que je parle souvent de la mort?

LE PÈRE

Mais non, elle exagère !

LA PETITE FILLE (Criant presque.)

Si ! Elle parle de la mort !

Elle en parle d'une manière terrible, comme si c'était quelque chose de normal, que ça devait arriver de toutes les manières... demain peut-être...

MATHILDE (Elle est à son tour descendue sensiblement à la même hauteur qu'Eugénie.)

C'est vrai, je suis d'accord avec ma petite-fille, c'est agaçant à la fin cette tendance à philosopher qu'a toujours eu ma fille: la vie, la mort, l'amour, la vie, la mort, l'amour...

LA MÈRE (Avec simplicité et détachement.)

La mort ne me fait pas peur. J'ai vu la mort, je la connais, elle m'est arrivée et j'ai découvert que je n'étais pas mortelle que j'avais une âme et que je rejoindrai le grand tout.

LA PETITE FILLE (Elle l'observe comme un être étrange.)

Alors la mort ne te fait vraiment pas peur du tout ?!

LA MÈRE

Non! Si on me dit «tu dois mourir tout à l'heure », et bien, je me préparerai mais je n'aurai pas peur.

LA PETITE FILLE (Se bouchant les oreilles.)

Je ne veux pas entendre tes paroles, moi, je ne veux pas entendre parler de mort, je veux vivre! 
LA MÈRE (riant)

La mort n'est pas une fin. De toutes les manières elle t'arrivera comme elle arrivera à nous tous.

LA PETITE FILLE (En colère à son père.)

Alors elle parle de l'âme, de la vie après la mort, de toutes sortes de choses que toi le marxiste tu nies, et tu la laisses parler? Tu ne lui dis rien? Tu y crois aussi alors ? Mais nous savons bien tous que nous ne sommes là que pour vivre dans l'instant, que rien n'existe en dehors... dieu... l'au-delà... l'âme... la vie après la mort, contes et balivernes, enfin papa, c'est ce que tu m'as appris... je l'ai lu dans les livres !!!...

LE PÈRE

Elle était terrible cette route qui reliait l'île plate au volcan par delà la rivière salée.

Je conduisais la voiture que nous n'avions pas fini de payer et les Nègres des campagnes nous faisaient de grands signes de la main en me voyant moi, le Nègre savant, assez riche pour se payer une automobile avec cette femme belle et blonde dont les cheveux bougeaient comme des vagues au vent.

LA MÈRE

On s'élevait rapidement à plus de 700 mètres au dessus de la mer. On voyait les îles si proches dans tout le bleu du ciel et de la mer, que je pensais souvent, qu'il suffirait de le vouloir vraiment, pour plonger au milieu d'elles comme un poisson volant.

LA PETITE FILLE

Et toi qu'est-ce que tu pensais des histoires de Blancs et de Noirs?

LA MÈRE (Riant de son rire insouciant et libre.)

Je les saluais de la main!

Une bonne fois pour toutes ma chérie: les hommes ne se distinguent qu'apparemment par la couleur de leur peau, la texture de leur cheveu, la transparence de leur prunelle, ou par le rythme de leurs musiques. Les hommes sont pareils du Nord au Sud et d'Est en Ouest: humains... horriblement.

LE PÈRE

La route était libre, j'avais plaisir à prendre les tournants en suivant bien les courbes. Tout d'un coup, ce camion s'est trouvé face à moi descendant une ligne droite complètement sur sa gauche à lui... Je n'ai pensé qu'à l'éviter, me jetant dans le fossé, la voiture s'est enfoncée dans le talus et... ta mère... ta mère s'est envolée par la portière, sa tête en retombant est venue frapper le poteau électrique. Elle était couverte de sang, désarticulée comme les poupées que l'on t'offrait et auxquelles tu arrachais la tête et ouvrais le ventre... je l'ai cru morte...

LA PETITE FILLE

Je ne faisais pas partie du voyage.

Je ne sais plus pourquoi.

Vous deviez rentrer le soir. Le soir tombait et vous ne rentriez pas.

J'errais dans le jardin, habitée par un sentiment funeste comme est funeste la rupture du jour dans l'île où toute lumière s'écroule soudainement, sans défense, devant l'invasion de la nuit.

Une voiture est entrée en trombe dans le jardin du haut.

Un homme m'a demandé à parler à la mère de ma mère.

Je me suis approchée d'eux... j'ai entendu :

« Accident... fracture du crâne... coma. »...

L'issue semblait, elle aussi, funeste.

J'ai entendu aussi la mère de ma mère, cette femme qui n'avait jamais aimé les Noirs, 
dire que c'était ta faute papa... je l'ai détestée un peu plus et j'ai commencé à prier sans l'avoir jamais appris pour que tu ne meures pas, maman...

MATHILDE

Cette enfant n'a pas changé. Toujours une véritable peste...

EUGÉNIE

C'est sa perspicacité qui vous gêne?

LA MÈRE

J'ai senti que je quittais mon corps, sur la trajectoire d'une spirale qui me conduisait toujours plus haut vers une lumière intense et belle !

Je voyais la terre de très haut,

Je voyais les fourmilières humaines,

les hommes mesquins et jaloux,

les crimes atroces,

les viols, les vols, les maladies, les souffrances,

Je voyais les peuples s'entre tuer,

la mort cent fois recommencée sans qu'il en résulte aucun progrès pour l'homme, et je montais, montais vers cette lumière et plus je montais plus je me sentais délivrée de toute peur et de tout regret, délivrée du mal de vivre.

LA PETITE FILLE

Dès l'aube j'étais dans le jardin guettant l'arrivée de quelque envoyé. J'ai vu arriver marchant sur ses deux pieds nus couverts de poussière et tenant une boîte à la main au bout d'une ficelle, une femme assez âgée et qui me demanda à quelle heure et dans quel endroit se tiendrait la veillée funèbre pour ta mort, maman.

LE PÈRE

La nouvelle avait parcouru l'île et Miréna qui t'avait servie sept années était venue depuis Basse-Terre pour être sûre de te veiller la première.

LA PETITE FILLE

Je dis que tu n'étais pas morte !... seulement dans le coma...

À mes paroles elle ne fit que s'asseoir sur le muret qui bordait les rosiers et me dit qu'elle avait acheté, exprès, une paire de chaussures neuves pour ton enterrement c'est ce que contenait la boîte qu'elle tenait au bout de sa ficelle - soulagée que tu ne sois pas morte et regrettant sa dépense...

LA MÈRE

Soudain j'ai senti que l'on me tirait de nouveau vers la terre que je voyais se rapprocher dans les ténèbres. Je résistais de toutes mes forces, je ne voulais pas revenir, je voulais continuer à monter vers la lumière...

LE PÈRE

Un autre camion s'est arrêté et nous l'avons menée à la clinique du docteur $\mathrm{C}$. On la donnait pour morte, cependant on fit tout ce qu'on put: oxygène, massage cardiaque. Et on la déclara sauvée, mais elle restait dans ce coma... deux mois, deux mois elle fut absente.

LA PETITE FILLE

Papa me conduisit vers toi, tu venais de te réveiller.

LA MÈRE

Oui, peut-être... Je ne m'en souviens pas...

LA PETITE FILLE

Tu avais le crâne recouvert de bandelettes blanches comme une momie. Je ne voyais que tes grands yeux couleur de miel liquide et qui me regardaient avec absence et 
étonnement.

Tu me dis:

- On me dit que vous êtes ma fille...

Tu n'avais pas l'air d'y croire.

$\mathrm{Tu}$ fus très polie et gentille.

Tu ne me reconnaissais pas!

LA MÈRE

Oui, peut-être... Je ne m'en souviens pas...

LA PETITE FILLE

Et quand tu es revenue à la maison, ce fut pire...

LE PÈRE

Elle avait fini par accepter que nous soyons sa famille, mais elle n'avait pas fini de regretter qu'on l'ait obligée à revenir.

LA PETITE FILLE

Surtout quand elle avait trop mal à la tête. Tu descendais en disant :

- votre mère souffre de la tête les enfants...

et tu allais aussi jusqu'à la cuisine ou la buanderie pour le dire aux servantes.

Aussitôt il fallait que tout bruit disparaisse de la maison et nous errions comme des fantômes prenant garde que rien ne résonne.

Mais quand les chiens avaient hurlé et aboyé toute la nuit...

LE PÈRE

Les chiens sur l'île sont maîtres de nos nuits...

LA PETITE FILLE

Elle se prenait la tête à deux mains :

- Ces chiens, ces chiens, faites les taire!

Plusieurs fois tu l'as trouvée penchée sur le balcon de la terrasse du deuxième étage et regardant en bas...

LE PÈRE

Je l'ai trouvée, penchée et regardant le vide... quand je lui ai saisi les épaules pour la ramener en arrière, elle a tourné vers moi son visage et m'a dit qu'elle voulait mourir et retourner vers la lumière.

LA PETITE FILLE (Tout doucement.)

Je t'ai vu descendre l'escalier et... tu pleurais papa... tu pleurais... et je ne savais pas qu'un père pouvait pleurer.

LE PÈRE (Sans émotion exprimée.)

Alors tu m'as serré dans tes bras, petite fille, tu m'as serré très fort contre toi en me disant de ne pas pleurer.

LA PETITE FILLE (De même.)

Quand nous marchions dans les rues de cette ville, Paris, tu me tenais toujours par les épaules ou la main posée sur ma nuque comme pour dire que j'étais bien de toi. J'aimais la douceur et la force de ta main sur ma nuque.

Tu n'as pas répondu à ma question papa... Tu y crois toi à la vie après la mort ?

LE PÈRE

Il y a longtemps dans les campagnes, il est arrivé, lorsqu'un ami mourait, que les hommes se saisissent de lui la nuit venue, tout raide et tout mort qu'il était, le soutenant sous les aisselles, le transportent de case en case où ils toquaient 
bruyamment chantant, riant et pleurant tout à la fois. Les gens sortaient sur le seuil et régalaient la compagnie: À la santé du mort !!

Avant de boire ses amis n'oubliaient jamais de lui en verser une rasade...

LA PETITE FILLE

Alors ils croyaient vraiment qu'il vivait toujours et savait ce qui lui arrivait?

LE PÈRE

Croyances imbéciles... il n'y a rien après la mort.

LA PETITE FILLE

Rien c'est quoi?

LE PÈRE

Rien c'est rien, rien qu'on puisse imaginer, rien qu'on puisse concevoir.

LA PETITE FILLE

Ni paradis et pas d'enfer?

LE PÈRE

Le paradis est éphémère et l'enfer de toute éternité sur terre.

LA PETITE FILLE (En aparté. Disant cela elle sort.)

Alors pourquoi ceux qui sont morts me parlent dans mes rêves?

(Elle sort.)

LE PÈRE

Je me souviens quand elle est née. Elle était si petite dans le pli de mon bras, sa tête dans le creux de ma main, me fixant de son regard intense, m'interrogeant déjà sur sa place dans l'univers.

Quelle drôle de petite fille c'était. (Riant)

Alors que ses camarades, jouaient à la poupée, elle leur arrachait la tête et leur ouvrait le ventre pour savoir ce qui était dedans.

Les livres! Elle lisait tout, tout le temps.

Elle levait vers vous des yeux remplis d'images et vous questionnait sans cesse sur les choses les plus saugrenues.

Un jour, nous étions à table, et puis soudain elle nous demanda: « comment vous faites quand vous vous embrassez est-ce que vous mélangez vos langues?»

Nous n'avons pas su quoi dire et j'ai fini par lui répondre que cela ne la regardait pas.

Elle accueillit cette non-réponse avec un regard entendu qui mesurait notre malaise.

Ainsi les jours succédaient aux jours.

J'étais un homme heureux comme les hommes le sont, avec le désir d'autre chose toujours dans le cœur. Il fallait faire la révolution, sortir le pays de son endormissement.

J'entrais au Parti ${ }^{8}$. C'était un vrai combat. J'écrivais dans le journal du Parti, je me réunissais avec les camarades. À l'époque des élections nous devions défendre farouchement nos votes. Des combats pétaient, les grèves étaient souvent mortelles et j'avais l'impression d'être au cœur des choses.

Elle grandissait. Un jour elle frappa à la porte de mon bureau :

- Alors les Gaulois sont vraiment nos ancêtres?

J'ouvris son livre d'école. On y parlait des Gaulois, ancêtres des Français et des Caraïbes, premiers habitants de l'île qui se couvraient le corps de roucou?

Mais de ceux d'Afrique pas un mot... Mais de ceux d'Afrique pas un mot...

Alors je l'assis sur mes genoux et lui racontais ce que je n'avais jamais osé lui dire et que 
l'on taisait hermétiquement.

Ce passé maudit d'esclave.

Je nommais aussi Delgrès et le Matouba ${ }^{10}$. Je lui répétais ce que mon propre père m'avait dit: Nous n'avions pas été que des esclaves mais aussi des combattants.

Elle avait tout juste 6 ans.

LA MÈRE

Tu te souviens le jour où elle est entrée?

LE PÈRE

À hauteur de morne, notre chambre, une porte fenêtre au Levant...

LA MÈRE

Cela faisait un moment sans doute qu'elle nous regardait.

C'était cela qu'ils n'aimaient pas...

LE PÈRE

Ils?

LA MÈRE

Les blancs de ton pays, ils détestaient nous imaginer... au lit... ensemble...

LE PÈRE (Rageur et riant.)

Ça les rendait jaloux, tous autant qu'ils étaient, qu'une fille aussi belle soit ma femme... LA MÈRE

Ça les gênait vraiment... simplement d'imaginer ta main sur moi...

LE PÈRE

Je caressais la blancheur de tes seins.

LA MÈRE

Nous avons ensemble perçu sa présence.

Elle était au seuil de notre chambre, grave et émerveillée... contente elle était contente...

LE PÈRE

Je me rappelle son sourire. Elle nous tenait tout entiers nous aimant dans son regard...

LA MÈRE

Qu'est ce qui les gênait? Que nous soyons mari et femme, amant et amante? Que nous jouissions l'un de l'autre?

LE PÈRE

Non, tu l'as dit, tu l'as bien dit, que ma main noire caresse ta peau blanche, juste cela pour eux le contraste indécent du noir et du blanc.

LA MÈRE

Le noir inscrit comme un signe sur le blanc. Juste pour ça?

LE PÈRE (Avec fureur peut-être ou ironie.)

Celui qu'il était si confortable de considérer comme un sous-homme...

LA MÈRE (Riant)

J'aime le noir... c'est une belle couleur !

(Ils rient)

LA MÈRE

Et puis elle a refermé la porte, toujours nous souriant.

(On entend « À la claire fontaine » sur un rythme de léwoz.) 


\section{Scène 3}

(Mathilde et Eugénie assises chacune dans sa nacelle. Elles ne sont pas si distantes que certaines fois, en se balançant, elles se rapprochent assez pour s'effleurer peutêtre la main, mais ne le feront pas. Elles descendront toutes les deux de leur nacelle à un moment donné et iront s'asseoir sur le banc.)

MATHILDE (Très digne et très peinée de ce que sa petite fille a dit d'elle plus haut.)

C'est vrai, la petite dit vrai, je n'aime pas les Noirs...

EUGÉNIE

On s'en serait douté !

MATHILDE (Répétant ce que sa fille a dit d'elles deux plus haut.)

Ta grand-mère Eugénie avait reçu une éducation classiquement bourgeoise très catholique et très « bien pensante ».

Ta grand-mère Mathilde était une femme moderne. Elle prétendait ne se laisser faire par rien et par personne et avait décidé de survivre à tout et contre tous.

$\mathrm{Tu}$ vois, j'ai au moins réussi ça de bien: ma fille est capable de résumer nos deux vies en trois phrases.

EUGÉNIE

On reconnaît bien là les paroles d'une fille pour sa mère, la vérité ne visite pas toujours les paroles aimantes...

MATHILDE (De même et retrouvant peu à peu son assurance.)

Je ne vois pas pourquoi je ne dirais pas c'que j'aime ou c'que j'n'aime pas.

C'est toute la différence entre nous !

Toi tu as passé ta vie à faire semblant de ceci ou de cela!

Moi, quand j'aime, j'aime et quand j' n'aime plus... je passe à autre chose.

D'ailleurs ce n'est pas que je n'aime pas les Noirs en tant qu'hommes...

Enfin... tous les hommes sont des hommes, n'est-ce pas? Avec un sexe, là où il doit être... et un autre dans la tête !

IH IH IH IH !!

Nous sommes bien d'accord là-dessus, Eugénie!

Non... c'est que les Noirs et nous, sommes... si différents...

Notre manière d'être, nos habitudes,

Notre culture quoi!

EUGÉNIE (L'imitant.)

« Notre culture, quoi !»

Vous pourriez en dire autant de nous deux, Mathilde: Nous sommes pareilles, avec notre sexe, nos cœurs et nos ventres et pourtant nous ne nous ressemblons pas! Et savez vous pourquoi?

Ce n'est pas notre couleur, où notre éducation, non ma chère.

Ce qui vraiment nous fait différentes... c'est que, malgré tout ce que vous prétendez, vous aimez les hommes et que je ne les aime pas!

MATHILDE

J'aime les hommes... j'aime les hommes!

Pas tous les hommes!

Certains... enfin ça dépend !

Je crois plutôt que c'que j'aime c'est être aimée, c'est normal, non? 
EUGÉNIE

Comment ne les aimeriez vous pas! Après vous êtes mariée... trois fois... Dans notre milieu le sacrement du mariage était sacré, nous ne divorcions pas! Vous avez divorcé... deux fois.

Pourquoi l'auriez vous fait si vous ne les aimiez pas?

MATHILDE

C'est vrai, je me suis mariée plusieurs fois.

EUGÉNIE

Et vous les avez tous... aimés ? Seriez-vous capable de me dire, Mathilde, véritablement, ce qui vous a poussé à épouser TROIS HOMMES!

MATHILDE

Vraiment tu dis ça d'une manière ! Comme si je les avais mariés tous les trois en même temps ! Faut quand même pas exagérer...

Tu sais qui était le premier?

Un Belge appartenant à une grande famille de banquiers wallons...

EUGÉNIE

Wache ${ }^{11}$ ! D'après ce que m'a expliqué votre fille, la femme de mon fils, ce n'était pas lui le banquier, il travaillait dans la banque de ses cousins banquiers... Vous conviendrez que ce n'est pas du tout la même chose. Et vous l'avez quitté ?

MATHILDE

Je peux beaucoup pardonner à un homme, sauf l'ennui.

Je me suis tant ennuyée à Bruxelles... Je comptais les passages des tramways dans l'avenue depuis les fenêtres de mon appartement, en berçant ma fille bébé qui hurlait d'ennui elle aussi.

Je me suis enfuie sans rien lui dire. Je détestais sa souffrance. Je n'ai rien demandé, ni pension, ni biens. J'ai divorcé très vite.

Tu sais ça, Eugénie, que le divorce existe et n'est pas pour les chiens?

J'étais libre, Libre!!

Ah! La liberté ! cette chose qui vous saute là, au milieu de la poitrine et au milieu du ventre, quand toute la vie est à nouveau ouverte devant soi, et toutes les directions à prendre !!

EUGÉNIE

$\mathrm{Kip}^{12}$ ! Sentiment qui ne dure qu'un moment... ensuite il faut choisir quel chemin prendre... et le sentiment de liberté fait place à celui du devoir... Et l'autre, le deuxième?

MATHILDE

Un Français. Un technicien, une tête, des mains... Ce fut un amour fou... oh lala, avec lui on ne s'ennuyait pas... Il aimait la vie, plus qu' moi-même. Tu n'peux pas rêver les jours et les nuits... brûlés, pfuitt... une allumette... c'était... C'était un amant - Eugénie, ne prend pas ton air de sainte-nitouche - d'une invention rare...

EUGÉNIE

Avec le portrait que vous en faites, c'était l'homme idéal? Alors je ne comprends pas pourquoi vous l'avez quitté celui-là. Et tu as préféré le troisième, celui avec lequel tu as débarqué... 
MATHILDE

$\mathrm{Tu}$ m'en veux encore tant que ça, mère du mari de ma fille, d'avoir été toujours une femme, alors que tu t'étais résignée à être vieille et oubliée ?

EUGÉNIE

J'apprécie ton art de détourner la conversation mais je continue à ne pas comprendre comment tu as pu te marier à cet homme vulgaire, malhonnête et... vicieux. D'ailleurs tu ne m'ôteras pas de l'idée qu'il t'a si vite accompagnée pour mettre entre Paris libéré et lui... quelques distances...

MATHILDE

Il était peut-être tout ça, mais ses désirs correspondaient exactement aux miens. Ah ! Ce qu'on a pu rire!!

EUGÉNIE

... marché noir, collaboration... enfin dieu reconnaitra les siens... à part cela, tu l'as installé chez toi, alors que vous n'étiez pas encore mariés, il avait plus de dix ans de moins que toi, et haïssait mon fils, ça, je n'arrive pas à te le pardonner...

MATHILDE

Et toi, avec ton unique mari, tu vas peut-être me dire que ce fut le grand amour !

EUGÉNIE

Oui ! Je l'ai aimé !...

Figure-toi que j'avais le choix: Tu ne peux t'imaginer la quantité d'hommes qui demandaient ma main.

J'avais décidé d'être difficile...

Dans l'habitation de mon père aux Abymes, j'attendais, me chantonnant une des chansons françaises que La Reine chantait à mon père quand il était enfant et qu'il m'avait apprise.

«Ah! Que j'ai douce souvenance

Du joli lieu de ma naissance,

Mon frère, qu'ils étaient doux les jours de France

Ah mon pays sois mes amours toujours... »

MATHILDE

Ah! Vraiment la reine était votre grand-mère ?... et tu dis que c'est moi qui exagère ?... EUGÉNIE

La reine, parfaitement! Mon grand-père et ma grand-mère, des habitants de haute souche, étaient nommés Roi et Reine des Abymes aux frontières de Bordeaux Bourg et du Moule.

Et, Mathilde, ou ka énervé mwen... si ou pa pé bouch aw ti brin an pé ké continué ${ }^{13}$ !

Bon!

MATHILDE

Bon, bon, pas la peine de t'énerver comme ça ! Je n'vais plus t'interrompre, continue-la ton histoire...

EUGÉNIE

Alors... Leurs propriétés couvraient des hectares et des hectares de terre à cannes, de jardins à légumes et de vergers d'orangers verts et de citronniers blancs...

MATHILDE (Très énervée.)

"Des citronniers blancs, des hectares et des hectares", et pourquoi pas « cerisier rose et pommier blanc "? Puis quoi encore? Dans une île aussi minuscule cela ne fait jamais que terres très étroites, vite bornées, sans issue... et malgré ton éducation, Eugénie, 
aucun blanc ne voulait épouser la bâtarde noiraude d'un grand blanc... même reconnue!

EUGÉNIE

Tu es mauvaise, Mathilde...

MATHILDE

Non! C'est la vérité qui l'est ! Et tu as passé des années, des mois, des jours, des heures, des minutes sur cette véranda, trompant ton ennui, donnant des ordres à tes servantes, telle sœur Anne ne voyant rien venir, dans l'attente du prétendant idéal... Celui qui serait le... moins noir...

EUGÉNIE (Sur le ton véhément de celle qui subit l'offense.)

Ce serait bien simple. Mais il ne me suffisait pas à moi, qu'il soit moins noir, il était important qu'il soit éduqué, cultivé que j'ai quelque raison d'avoir pour lui du... respect.

Ma pauvre Mathilde, ce n'était pas seulement une question de couleur. J'attendais aussi quelqu'un de mon éducation! D'ailleurs tu l'as connu et tu ne peux nier qu'il avait de l'allure, beaucoup de classe.

C'était un Noir clair... presque mulâtre... avec quelque chose de chinois... éduqué... un instituteur... il possédait déjà une belle collection de livres...

MATHILDE

Je crois que c'est cela qui a aussi séduit ma fille chez ton fils, les livres, les livres, les livres...

EUGÉNIE

Mes servantes m'avaient annoncé sa visite depuis une semaine déjà. À chaque fois qu'un homme se présentait pour m'épouser, je trouvais en elles des commères avisées, sachant tout de leur cour et de leur arrière-cour, tout de leur parentèle, tout de leurs vices, tout de leurs qualités... si l'on pouvait leur en soupçonner quelqu'une !

MATHILDE

C'est bien c'que j'détestais sur cette île: On savait tout d'tout l'monde...

Ah! Panam ! J'en avais marre en pensant à toi dans cette île ridicule, avec tous ces gens qui nous regardaient comme des habitants de la lune, nous qui n'étions ni blancs créoles, ni nègres, ni mulâtres et qui n'appartenions pas à la famille une telle ou une telle...

J'étais la parisienne, la mère de l'autre parisienne, ma fille, celle qui marchait si vite dans les rues que l'on croyait toujours qu'elle avait oublié sa casserole sur le feu... et je rejoignais ce jeune couple de mariés, très beaux, très intelligents, qui s'aimaient comme Roméo et Juliette, avec seulement un tout petit quelque chose qui gâchait le tableau, lui était noir, et elle... blanche...

EUGÉNIE

Vous, les blancs, ce que vous appelez notre nonchalance, vous n'y comprenez rien et peut-être nous-mêmes avons nous oublié ce qu'il y avait d'insolence et de résistance dans cette manière de prendre le temps, d'occuper le temps de chaque geste comme pour défier les ordres et le rythme du travail forcé... Je continue mon histoire ou bien tu m'as seulement interrogée sur moi pour pouvoir parler de toi ?

MATHILDE

Malgré tes années de grand sommeil je vois que tu as su conserver toutes tes épines !!! EUGÉNIE

Imagine-toi... Il est entré dans le jardin de mon père sur sa jument alezane. Il portait un 
costume clair et le casque colonial blanc... comme tous les hommes à cette époque. Mon père l'a reçu dans la bibliothèque... Une maison sans livres...

MATHILDE

... est une maison sans âme... Oui je sais ! J'ai assez entendu ton époux me répéter ça de son air supérieur...

EUGÉNIE

... est une maison sans âme... mais oui...

MATHILDE

Ne le singe pas trop! Tu sais très bien qu'il t'associait à moi dans son mépris des femmes!!

EUGÉNIE

C'est bien ça! Tu ne supportes pas que les autres aient aussi un destin...

MATHILDE

Je me rappelle ce livre que j'ai feuilleté un jour chez toi :

Sur le cahier de pages que ton époux faisait brocher au début de chaque ouvrage, il avait inscrit de sa grande écriture violette :

« Nota. Le jeudi 5 Décembre 1935, matin, j'ai trouvé que les 32 premières pages du livre ont été enlevées par une vandale... de la maison... (je ne sais encore laquelle...)

Vendredi 6 Décembre 1935, 7 heures du soir. »

Nous n'étions rien d'autre que des vandales pour lui, tu t'en souviens maintenant?

EUGÉNIE

MATHILDE

Et puis il n'a jamais voulu se marier à l'église !

EUGÉNIE

Ma petite-fille a raison, tu es méchante !

MATHILDE

N'oublies pas que ta petite-fille est aussi la mienne... Et puis, c'est vrai! Il n'a pas voulu se marier à l'église !!

EUGÉNIE

Mais tu sais très bien comment cela s'est passé, alors pourquoi tu insistes comme ça ? Quand il a demandé ma main, il m'a dit qu'il s'agirait d'un mariage républicain, qu'il ne faisait confiance ni aux curés ni au pape.

Il disait que la religion était une menace pour l'homme car portant soi-disant réponse, même aux questions qui n'étaient pas encore posées.

En particulier il méprisait les curés qu'il jugeait hypocrites et menteurs.

MATHILDE

Je crois que c'est pour ces quelques petites choses là que je l'aimais bien malgré tout: nous avions tous deux le même mépris pour la papauté...

EUGÉNIE

Il était rousseauiste, républicain et démocrate "pourvu que le peuple soit libre et éduqué, répétait-il, et le monde changera!».

Imagine-toi la sensation que me firent ses paroles: Personne ne m'avait jamais parlé de ces choses là.

Mes modèles avaient été la Reine, mère de mon père et ses filles, mes tantes, si fortes en dévotion, qui ne manquaient ni pater ni ave, ni messes des rameaux, ni procession de la 
vierge, ni chemin de croix, ni rosaire.

Et voilà qu'il entrait dans ma vie comme un coup de vent venu de la mer précède les fortes pluies de novembre. Il était plus aristocratique que les aristocrates qui fréquentaient jadis l'habitation de mon père, plus cultivé aussi, plus provocateur et arrogant, ne respectant rien, «ni dieu, ni maître ", disait-il, Il commandait ses livres à Paris et Amsterdam... Il me sembla que c'était là l'homme idéal.

MATHILDE

L'homme idéal, l'homme idéal... mais tu sais bien que ça n'existe pas ! Et puis arrête de pleurnicher sur ton passé, Eugénie, ça m'énerve... Tu oublies les autres femmes... Toutes les autres femmes avec lesquelles il te trompait à la vue et au su de tout le monde... toutes ces femmes auxquelles il a mis dans le ventre ses enfants de «dehors » comme on dit chez vous.

EUGÉNIE

Non, je n'ai rien oublié !!

Mèm gen an éméye, mèm jan an haye li...

Aussi vite je l'ai aimé, aussi vite je l'ai haï... Et tes hommes, ils ne te trompaient guère, je suppose?

MATHILDE

Je ne leur en laissais pas le temps...

EUGÉNIE

Lorsqu'il a repris son commerce avec une maitresse que j'appelais la " petite vache ", je crus que dieu me punissait pour ce mariage républicain... Je l'ai supplié, s'il m'aimait encore, de m'accorder la bénédiction chrétienne de notre union... il n'a jamais cédé.

Après la naissance de mon deuxième fils, j'ai fermé ma porte à clef.

Cela l'a rendu furieux, et puis il s'est senti soulagé, je suppose, de ne plus être obligé de jouer la comédie...

LA PETITE FILLE

J'ai descendu dans mon jardin,

J'ai descendu dans mon jardin,

Pour y cueillir du romarin,

Pour y cueillir du romarin,

Gentil coquelicot mesdames, gentil coquelicot nouveau...

EUGÉNIE

Écoutez ! Mathilde, la petite nous appelle dans son rêve...

MATHILDE

Encore cette histoire de jardin, décidément, vous y tenez dans votre famille...

EUGÉNIE

Elle vient vers nous...

MATHILDE

Cette enfant nous entend peut-être.

EUGÉNIE

Et cela te gêne qu'elle saisisse nos pensées?

MATHILDE

Tais-toi... la voilà. 


\section{Scène 4}

(Couchée sur le pont, la petite fille. Le pont s'enlève peu à peu dans les airs et s'immobilise pareil à un croissant de lune, entre la balancelle de Mathilde et celle d'Eugénie.)

LA PETITE FILLE (Chantant pendant que le pont s'élève.)

J'ai descendu dans mon jardin, J'ai descendu dans mon jardin, Pour y cueillir du romarin, Pour y cueillir du romarin, Gentil coquelicot mesdames, gentil coquelicot nouveau...

(S'asseyant sur le petit pont et découvrant ses voisines... sur un ton badin.)

Ah ! Enfin ! Vous êtes là vous deux ?... Depuis le temps que je vous appelle...

Ah! Alors comme ça, vous vous faites la conversation...

L'éternité apporte donc un certain changement dans la manière des hommes...

Car, ma grand-mère du côté blanc et ma grand-mère du côté noir, Je ne me souviens pas vous avoir jamais vu vous parler.

En quelques rares occasions, vous vous êtes retrouvées dans le même lieu, faisant semblant de ne pas vous considérer, mais chacune savait ce que faisait l'autre comme si elle eut été l'autre même, c'est cela n'est-ce pas, je l'ai bien deviné ?

MATHILDE

Je ne te le fais pas dire. Elle soupesait le poids de mes bijoux, détaillait la finesse de mes bas, soupçonnait l'onctuosité de mon rouge à lèvres et humait en sourdine la rareté de mon parfum...

EUGÉNIE

Elle épiait chacun de mes gestes cherchant à savoir de quelle nature ils étaient, comment il se faisait qu'ils puissent être à ce point inévitables...

MATHILDE

C'est vrai, je n'avais jamais rencontré quelqu'un tellement à sa place que j'en étais mal à l'aise...

EUGÉNIE

Elle avançait avec des jambes légères qui soulevaient sa jupe, même lorsqu'il n'y avait pas un souffle d'air, on avait toujours l'impression que ses vêtements allaient la quitter et qu'elle serait bientôt nue sous le regard de tous.

MATHILDE

Elle jouait son rôle à la perfection, régnait sur un peuple de servantes, considérait son mari avec un mépris bien élevé mais néanmoins tuant, et ils se vouvoyaient tous deux avec une froideur qui donnait le vertige.

EUGÉNIE

Elle suivait le regard des hommes sur elle dans tous les miroirs, leur faisait savoir qu'elle savait qu'ils la désiraient... sans rien leur céder pourtant... quelle garce!

LA PETITE FILLE

Vous n'allez pas vous disputer...

MATHILDE

Mais on ne se dispute pas ma chérie, on discute... 
EUGÉNIE

On se dit des choses qu'on ne s'est jamais dites et je ne sais pas si c'est vraiment une bonne chose...

Bon... Dis-moi ce qui ne va pas, petite, si je peux t'aider je le ferai.

MATHILDE

Mais bien sûr, voyons, je n'ai jamais dit le contraire, s'il est possible d'aider quelqu'un on le fera bien pour toi, alors raconte...

LA PETITE FILLE

Vous êtes parties si vite, je me suis retrouvée seule entre eux deux, papa et maman, leurs paroles apparemment légères et leurs silences...

MATHILDE

Je l'ai toujours dit, il faut se marier dans son pays, dans son milieu, avec des gens de sa race...

EUGÉNIE

Et on peut dire, Mathilde, que vous avez largement pratiqué cet adage !

LA PETITE FILLE

L'étrangeté de leur couple tissait tout autour comme un grand espace, une terre à part... Nous avions quitté l'île pour toujours, on dirait.

Quelques amis nous visitaient, armés de propagande colorée aux senteurs socialistes qui vantaient la Russie soviétique, en Chine une nouvelle révolution...

L'île me manquait tant que je passais mes nuits à la revisiter en rêve et à vous chercher sur les mornes de mon enfance...

MATHILDE

... ça, on s'en est aperçu! Ta voix s'élevait jusqu'à nous, c'est très désagréable, quand on dort aussi profondément, d'être appelé comme ça!

LA PETITE FILLE

Une question s'imposa bientôt à moi comme la plus importante: quand sommes-nous éveillés et quand dormons-nous? La vie est-elle la vraie vie?

EUGÉNIE

Des questions, toujours des questions.

LA PETITE FILLE

Ce ne sera pas toujours ce matin froid du noir hiver, avant l'école, quand une lueur improbable ne vous permet même pas de croire que le soleil existe !

J'en avais la conviction ma vraie vie à moi, elle commençait lorsque j'avais posé la joue sur mon oreiller, égrenant mes souvenirs comme autant de trésors à jamais préservés de la mort et de l'oubli, et je plongeais dans le sommeil comme dans les livres qui ouvrent toutes les portes de tous les mondes passé, présents et futurs !!

EUGÉNIE

Bon dié bon, Mi on $\mathrm{ka}, \mathrm{mi}^{14}$...

MATHILDE

Tu sais bien que je ne comprends pas tout de ton créole...

LA PETITE FILLE

Elle a dit que je suis bizarre.

MATHILDE

Pour une fois je serai d'accord avec elle... C'est bien compliqué ton histoire !!

EUGÉNIE

Mais laisse la continuer! 
LA PETITE FILLE

Depuis trop longtemps mes nuits sont plus importantes que mes jours et pourtant mes rêves sont si affreux, que j'ai peur de m'endormir...

MATHILDE

Pour ta grand-mère et moi-même, c'est exactement l'état dans lequel nous nous trouvons toutes deux: crois-nous, notre nuit est notre jour...

EUGÉNIE

Mais enfin Mathilde, elle, elle n'est pas dans notre monde, elle est vivante !!

(Le pont et les balancelles sont descendus la petite fille saute la première, Mathilde et Eugénie se hâtent de la suivre...)

LA PETITE FILLE (Tantôt marchant tantôt courant, Mathilde et Eugénie s'essayant à la suivre.)

Des rêves féroces et si vrais... Je me réveille le corps dur comme du bois et le cœur torturé.

Je fuis, je cours dans des forêts jamais assez profondes... terreur, et arrachement. La pire des choses c'est l'entravement... torture humiliante des liens... je serai une femme, sans collier, ni bracelets, ni guêpière...

Je me dis que peut-être mon corps se souvient des temps d'esclavage et j'ôte de mon corps ces poids.

(La petite fille s'assoit au sol, Eugénie et Mathilde s'assoient à leur tour dans un demi cercle.)

EUGÉNIE

Et alors? Dans tes rêves?

LA PETITE FILLE

Je rêve le viol... et... plus que tout... je ne pense qu'à rester vivante, je lutte pour ne pas être repoussée dans le ventre obscur du non-être.

Ce n'est pas digne... je sais... Mais j'y peux rien...

MATHILDE

La dignité, la dignité, voilà encore un mot qu'ont inventé les hypocrites. Pour être digne il faut être vivant, rester vivant c'est le premier devoir...

LA PETITE FILLE

Je me souviens aussi de la faim...

Pourtant je n'en ai jamais souffert, il me suffit d'ouvrir le frigidaire, il y a du beurre, des œufs, du jambon, de la viande... dans mes rêves, je me souviens d'avoir eu faim à m'en sucer le sang à travers la chair de mes joues à l'intérieur de ma bouche... je faisais comme ça... regarde.

(Elle avance la bouche en cul de poule et aspire ses joues à l'intérieur en fermant les yeux.)

MATHILDE

C'est exactement ça... quand on a vraiment faim, on rêve d'être vampire de soi-même... LA PETITE FILLE

Je l'ai lu dans un livre : Certaines se sont suicidées qui sont de mes ancêtres et que je ne connais pas..

Et bien moi, dans mes rêves, je ne me suicide pas... je me tends vers eux comme une femme couleuvre.

Qu'ils n'aient plus de raison d'exercer leur force... 
Je ne ressens alors ni douleur, ni peur, ni haine, je m'applique seulement à rester vivante...

C'est affreux non? Lorsque je suis réveillée, couverte de sueur et le visage mouillé de larmes, le cœur battant à grands coups dans ma poitrine, je suis remplie de désespoir... EUGÉNIE

Alé, alé pitit mwen, pa chaviré kow'aw ${ }^{15}$.

Et si tu veux savoir... ma mère, tu le sais, était une africaine, une dont le sang n'était pas mêlé... Ah yayaye... petite... Aïe mon dieu... Que de peine...

"Si noire que bleue ", dans ses yeux se reflétaient les nuages et même le vent ondoyant sur les champs de cannes, je n'oublierai jamais la tristesse qu'on y lisait et qui faisait douter de toute joie, de la vie même...

C'est malgré moi qu'un jour elle me raconta ces choses, et je détestais qu'elle me parle de ce temps d'infamie et de deuil:

"Certaines d'entre elles, les plus sauvages ou les plus douces... il se trouvait des cas dans ces deux extrêmes... n'avaient de cesse que de cesser de vivre.

Elles servaient peu de temps le poids du corps des hommes.

On les retrouvait mortes.

On ne savait comment.

Quelque fois elles s'arrangeaient pour sauter par dessus bord et disparaissaient dans les vagues en poussant un grand cri de triomphe.

Pour ne pas perdre la marchandise on ne les détachait plus quand on les menait sur le pont.

On leur jetait quelques seaux d'eau salée.

On écartait leur cuisse et commençait le va et vient douloureux en leur corps. »

LA PETITE FILLE (Le visage tordu de douleur.)

Comment peut-on faire cela à des êtres humains, comment ?

EUGÉNIE

D'autres, comme tu le rêves, souffraient et gardaient en elles la force de survivre malgré tout.

LA PETITE FILLE

Et quand naissait leur bâtard...

EUGÉNIE

"Certaines d'entre elles, les plus sauvages ou les plus douces... il se trouvait des cas dans ces deux extrêmes... accueillaient leur enfant dans un grand dégoût de vie.

Si on ne les retirait pas de leurs mains, elles les étranglaient sans larmes et s'ôtaient la vie de quelque manière violente et sans rémission. »

LA PETITE FILLE

Mais il s'en est trouvé pour les aimer, eux qui étaient nés de la violence et du rut...

EUGÉNIE

Il s'en trouvait, c'est vrai, qui maitrisant leur grande haine prenait pitié des petits êtres. Elles les aimaient... jusqu'à ce qu'on les arrache à leur bras pour les vendre.

LA PETITE FILLE

Il ne faut pas oublier ça.

Je le dirai à mes enfants.

Je demanderai à mes enfants de le dire à leurs enfants.

Il faut que nous nous souvenions de toutes ces femmes, nos mères anciennes dont le tombeau n'est pas connu et qui ont nourri de leur chair les grandes plaines au sol noir et rouge où poussent les cannes. 
MATHILDE (Avec une certaine rage.)

Oh la la Bon !... Bon, Bon, c'est vrai l'esclavage... J'trouve ça écœurant, dégueulasse... Bon, mais pour ce qui est du viol, il n'est pas nécessaire d'être noire, ni esclave: les blanches en ont eu autant leur compte... Temps de guerres ou temps de paix! Tout est bon pour forcer leur orifice... AH ! AH AH AH !!

Ce n'est pas une question de couleur, ma fille: Les femmes sont faites pour être violées et les hommes pour être des violeurs, ouais, c'est exactement ça que j'ai compris dans toutes leurs histoires depuis la nuit des temps...

Et ne me dis pas, Eugénie, que tu ne le sais pas...

EUGÉNIE

De quoi vous plaignez-vous, Mathilde, ce n'est pas ainsi que vous les aimez ?: des violeurs en puissance... et arrêtez de vous donner le beau rôle. Il faut sans doute que nous admirions votre force. Mais qu'avez-vous gagné finalement?

MATHILDE

Ma vie fut sans doute plus drôle que la tienne, et si tu as duré quand même tout ce temps, c'est que l'ennui ne tue pas, bien que j'ai prétendu le contraire.

EUGÉNIE

Si les vomissures vous égaient c'est que vous n'avez pas d'odorat...

MATHILDE

Contrairement à toi, je n'ai pas attendu 30 années de ma vie perchée sur une véranda à attendre qu'un homme pas trop noir et ayant quelques livres, vienne demander ma main à mon père.

Je n'ai fait aucun rêve de prince charmant, moi, j'ai toujours su qui étaient les hommes, exactement.

Il suffisait que je croise leur regard pour connaitre dans leur amour la part de chair et la part d'âme.

Mais tu te trompes Eugénie, généralement je n'aime pas les hommes, je les trouve communs, menteurs, prétentieux et souvent très laids...

LA PETITE FILLE

C'est vrai ça! Je me dis souvent que je ne dois pas appartenir tout à fait à la race humaine pour trouver tant d'êtres si étrangement laids...

EUGÉNIE

Grossiers, égoïstes et fourbes...

MATHILDE

Lâches et sans talents...

LA PETITE FILLE

Quelque fois cette laideur même m'attire... moi aussi je suis un être étrange, né d'un mélange proscrit.

MATHILDE

Je suis comme toi, petite fille, j'ai survécu à tous les viols, j'ai décidé de rester vivante, de faire partie des plus forts: résister, survivre, et, au bout du compte, obtenir ce que je voulais.

LA PETITE FILLE

$\mathrm{AH}$ ! Quand ça t'arrange tu dis que je te ressemble, mais quand tu crois lire dans le regard des autres le reflet de mon étrangeté...

MATHILDE

Arrête, arrête !! Ça tu l'inventes !! 


\section{LA PETITE FILLE}

Non, c'est vrai! D'ailleurs un jour je t'ai rendu visite dans ta bonne ville de Meaux. Nous marchions, échangions quelques paroles sur ta fameuse endurance qui te voyait si vieille et pourtant munie de toutes tes dents, quarante deux, pas une de moins, authentiquement tiennes.

J'essayais d'être gentille et je t'ai dit quelque chose comme: «ô grand-mère, comme vous avez de belles dents !! »

MATHILDE

J'ai toujours eu une excellente santé !

LA PETITE FILLE

Et tu m'as répondu: « Nous, nous sommes de bonne race ».

MATHILDE

Dans notre famille nous vivons vieux et vigoureux...

LA PETITE FILLE

Je n'aime pas cette manière là. Quand on dit cela, c'est comme si l'on disait que les autres ne sont pas de bonne race !! Et moi alors? Dans quelle race tu me mets moi ? Si tu n'aimes pas les Noirs, comment peux-tu m'aimer moi qui suis le produit de ce mélange, en fait, j'ai toujours lu dans ton regard un sentiment bizarre, tu m'a toujours perçue comme un être différent de toi, et je suis d'accord avec toi!

MATHILDE

C'est pas vrai, je t'ai aimée, même si je n'ai pas su te le dire, et quand je dis dans notre famille, je parle aussi de toi...

LA PETITE FILLE

C'est pas vrai ! Je suis de ta famille quand ça t'arrange et je suis d'une autre race quand ça t'arrange aussi !!

EUGÉNIE

Parlons en de ta famille, Mathilde... Tu nous en as peu dit...

MATHILDE

Mais je me fous de la famille, c'est toi Eugénie, qui es obsédée par qui était le père de ton père et les ancêtres si vertueux qui ont précédé ta venue sur terre...

LA PETITE FILLE (Avec vivacité et plaisir.)

Ah! Mais moi je sais, je sais... Maman m’a raconté... Le père de sa mère possédait un cirque et mon arrière arrière grand-mère était danseuse écuyère à cheval...

EUGÉNIE

Voyez-vous ça! Un cirque...

LA PETITE FILLE

Ils aimaient les chevaux, les élevaient, les dressaient, dansaient avec eux, voltigeaient de la croupe à l'encolure et couraient à leurs côtés aussi vifs et légers que s'ils appartenaient à une espèce tout à fait étrangère à la terre...

EUGÉNIE (Éclatant d'un rire vengeur et aigu.)

Des tziganes !!!... Ta famille était tzigane... j'ai lu quelques romans où ils figurent... voleurs d'enfants, voleurs de poules... errants... et sales, très sales... Je comprends pourquoi tu es jalouse de moi et de mes origines, tu n'as jamais été qu'une saltimbanque déguisée en parisienne...

MATHILDE (Sur le ton de la protestation véhémente.)

La famille de mon grand-père possédait un des plus grands cirques du monde! Qu'est- 
ce qu'il y a à dire à ça ? Il sillonnait l'Europe de la Baltique à l'Atlantique, toutes les capitales... mais ils n'étaient pas tziganes...

EUGÉNIE

Tout est toujours «grand» avec toi... (La singeant.) «les plus grands banquiers de Bruxelles, un des plus grands cirques d'Europe!» Je vois que ta mégalomanie n'a pas cessé dans notre vie après la mort !...

MATHILDE

Et toi, tu ne t'entends pas et «la reine ma grand-mère " par ci et « le roi mon grandpère par là !! » Ils ne te reconnaissaient même pas !

EUGÉNIE

Mais leur fils, mon père, m'avait reconnue moi, et tous mes frères et sœurs, j'étais sa fille, née de Libre ${ }^{16}$, je portais son nom!

MATHILDE

Parlons-en de ton nom... il avait un drôle de son ce nom, un son juif...

EUGÉNIE

Tous ceux qui portent ce nom ne le sont pas...

MATHILDE

Mais sûrement tous l'ont été...

EUGÉNIE

Ils venaient de Bordeaux, et de Franche-Comté, étaient chirurgiens militaires, furent corsaires sur les vaisseaux du roi contre les pirates entre Curaçao et Cuba, de la noblesse depuis nanni - nannan ${ }^{17}$. J'ai tous les papiers, les sceaux, les certificats de mariage et de baptême.

MATHILDE

Et moi je te dis que part de tes ancêtres n'étaient que juifs venus chercher bonne fortune aux Amériques...

EUGÉNIE

Et ils n'ont pas été les seuls!

LA PETITE FILLE

Vraiment mes grands mères, Je rêvais de vous depuis longtemps. Grand-mère Eugénie, je peignais tes longs cheveux qui descendaient jusqu'en bas de tes reins tandis que tu me contais et re-contais l'histoire de mon père qui refusa d'apprendre à lire et à écrire jusqu'à neuf ans avant que de devenir un grand $\mathrm{Grec}^{18} .$.

EUGÉNIE

Cette histoire est vraie.

LA PETITE FILLE

Quant à toi, mère de ma mère, j'imaginais que peut-être tu étais capable d'amitié pour moi et puis j'aimais ton air de dominer les hommes et de les rendre totalement stupides...

MATHILDE

Mais c'est vrai je t'aime...

LA PETITE FILLE (De plus en plus en colère.)

Et puis voilà, je vous ai appelées, vous venez dans mon rêve et je vous vois telles que vous êtes, pareilles toutes les deux malgré vos soi-disant différences: de vraies sottes, rétrécies de la cervelle, égoïstes et menteuses...

MATHILDE

Cette enfant est vraiment mal élevée. Eugénie, dis à ta petite fille de tenir sa langue ! 
LA PETITE FILLE (Sautant autour de Mathilde comme un indien autour d'un totem.)

$\mathrm{Tu}$ vois, tu vois, je l'avais bien dit, quand je te dérange je ne suis plus ta petite fille. Ah que tu es bête !!

EUGÉNIE

C'est vrai, elle est bête, mais c'est quand même ta grand-mère, alors un peu de respect, jeune fille...

LA PETITE FILLE

Je déteste le respect, je ne vous respecte pas, je n'avais que mes souvenirs et des lambeaux d'autres vies que je retrouvais dans mes rêves et voilà que vous m'apportez la preuve de ma solitude absolue malgré tous ces ancêtres dont vous êtes la descendance. Celui que j'aurais dû appeler, c'est grand-père. Lui il m'a toujours dit la vérité... EUGÉNIE

Cette petite est folle... déjà toute enfant, elle partait avec des bandes de garçons jusqu'à la Lézarde ${ }^{19}$, vers les roches blanches, pêchait les wassous ${ }^{20}$ à la main, piégeait les grives à la glu, chassait les merles et les kiows à la carabine à plomb, sifflait comme un homme et refusait obstinément mes ordres et mes conseils...

LA PETITE FILLE

Je m'en souviens de tes conseils : «Ne grimpe pas aux arbres, tu n'es pas un garçon. Ne cours pas! Tu vas déchirer ta robe. Ne siffle pas! Ça porte malheur. » Ah! Oui ? Et quel malheur grand-mère?

«Fille qui siffle au bord de la rivière, la rivière déborde et emporte la maison. » IH IH $\mathrm{IH}$, je n'ai jamais cru à tes histoires...

MATHILDE

Ton grand-père, vraiment? Ce grand amateur de femme, ce misogyne, qu'est-ce qu'il a pu te dire ? Tu rêves pour de vrai cette fois...

(Une lumière très douce nimbe peu à peu les cintres et deviendra de plus en plus forte.)

\section{LA PETITE FILLE}

Non! c'est la vérité... Un jour que j'étais petite, à la suite d'une visite à une imprimerie ou fabrique de cacao où il nous avait conduites, ma sœur et moi, il nous prit sur ses genoux, mais au lieu de nous conter compè Zamba et compè Lapin ${ }^{21}$, il nous dit comme chuchotant quelque secret mais avec force et conviction :

«Écoutez bien ce que je vais vous dire: Méfiez vous des hommes, ce sont des menteurs invétérés. Ne dépendez jamais d'aucun d'eux, ayez un métier, conservez votre nom. » MATHILDE

Ah! Le vieil hypocrite, quel remord pouvait bien le travailler pour qu'il se dévoile de la sorte...

EUGÉNIE

Et te livre le seul secret capable de préserver la dignité des femmes...

LA PETITE FILLE

Ce fut son unique héritage, avec un vieux livre aux pages sèches comme feuilles de mahogany ${ }^{22}$ en leur automne et qui tombent en poussière quand on les froisse.

Il y a des notes à l'écriture violette, et une phrase étrange où il traite quelqu'une de vandale...

MATHILDE

Nous connaissons déjà cette histoire. 
LA PETITE FILLE

Alors vous n'avez rien de plus à m'apprendre?

EUGÉNIE

La vie n'apprend rien qu'on ne sache déjà, intimement: on sait l'amour, on sait la mort, on sait les blessures quand elles vous arrivent, on reconnaît le goût des larmes...

MATHILDE

On joue seulement à ne pas savoir pour ne pas avoir trop peur...

LA PETITE FILLE

Je savais déjà tout ça avant de vous rencontrer, je l'avais lu dans les livres et vérifié dans mes rêves.

MATHILDE

Le passé est un pays que je te conseille de ne plus habiter, laisse-le de l'autre côté de la montagne, abandonne tous tes souvenirs, ne te retourne pas, et marche là où tu sens qu'il faut marcher...

LA PETITE FILLE

Abandonner mes souvenirs? Non jamais !!

MATHILDE

Et bien c'est comme ça... Il faut bien que tu l'apprennes un jour ou l'autre...

EUGÉNIE

Elle a raison, il faut laisser le pays des rêves, quitter la terre du passé, le présent tout entier t'appelle... retire-toi, petite fille...

LA PETITE FILLE

Alors c'est ça : Vous voulez que je vous oublie?

EUGÉNIE

Ne sois pas triste, mais nous sommes épuisées, ne viens plus nous déranger... laisse nous nous en aller pour de bon... cesse de croire que nous pouvons te donner les réponses que tu possèdes déjà...

MATHILDE

Tu vois la lumière Eugénie ? Ouais ! Ça flamboie quelque part vers en haut...

LA PETITE FILLE

Je m'en veux de vous avoir traitées de vieilles sottes, mais c'est vrai vous n'êtes pas très malignes...

(Eugénie et Mathilde donneront des signes de plus en plus évidents d'une belle impatience.)

MATHILDE

Oh lala! Petite, ne nous juge pas, on a quand même eu du courage pour supporter tout ça...

EUGÉNIE

$\mathrm{Tu}$ as raison, il y a quelque chose qui ressemble à de la lumière et qui est plus que de la lumière... il faut partir...

(On entend tour à tour "La goualante du pauvre Jean" mêlée à "Sûrement mon

bonheur ", vieille valse créole, un air chassant l'autre, comme porté par le vent.)

LA PETITE FILLE

On se reverra un jour? 
MATHILDE

Je n'sais pas c'que tu ressens, Eugénie, mais j'ai bien envie d'aller voir ce qui peut produire un tel éclat... Et la musique, tu l'entends la musique?

EUGÉNIE

Oui je l'entends, c'est bizarre de ressentir tant de joie et tant de peine... l'essence même du désir...

(Elles remontent dans leur nacelle et s'élèvent dans les cintres.)

MATHILDE

Adieu fille de ma fille... souviens-toi : « sans amour on est rien du tout »... Ah que cette lumière est belle... et que ce sentiment est doux...

EUGÉNIE

Retourne vers les vivants, fille de mon fils, tu nous portes dans toi, nul besoin de nous appeler encore !... Regarde comme tout s'éclaire dans le ciel et dans nos cœurs... MATHILDE (Comme une petite fille.)

D'ailleurs nous serons bientôt si loin que nous ne t'entendrons pas...

Ah Eugénie, comme c'est bon de se sentir de nouveau le cœur aimant...

(Elles disparaissent. La petite fille cherche à les apercevoir encore, juchée sur le pont, la musique s'amplifie et remplit tout l'espace. La petite fille est immobile, puis elle lève les bras joints vers le ciel dans la position d'un plongeur de haut vol et saute vers le haut. (Trempolin). Le noir absolu se fait.

Dans le silence on entend la petite fille.)

LA PETITE FILLE

Alors elles sont parties, et je suis restée seule, et au moment même où se faisait cette séparation, elles sont rentrées dans mon cœur à jamais réconciliées et moi réconciliée avec elles. Et j'ai su que j'étais bien debout dans le monde des vivants...

\section{NOTES}

1. Robe très près du corps, inspirée de la mode européenne du XVIII ${ }^{\mathrm{e}}$.

2. Le Léwoz est en Guadeloupe l'expression de l'héritage africain, rythmique, musical et corporel. Le Léwoz rassemblait les esclaves généralement après la récolte de la canne.

3. Puisque tu veux marcher, tu vas marcher.

4. Tu vas voir de quoi je suis capable.

5. Vieux français: colline.

6. Les feux de bois et d'herbes sèches.

7. Rythme issu de la créolisation des héritages musicaux africain et européen.

8. Il s'agit du parti communiste qui joua un rôle important en Guadeloupe jusqu'à la départementalisation. 
9. Graine du roucouyer de couleur rouge. Utilisée par les Caraibes qui s'en couvraient le corps et de nos jours dans la gastronomie et la pharmacopée.

10. Officier Mulâtre rebelle né à St Pierre en Martinique en 1766. Opposant déterminé au rétablissement de l'esclavage en Guadeloupe, il se fait sauter avec ses hommes en 1802 au Matouba et incarne la figure emblématique de la résistance à l'oppression.

11. Onomatopée du son d'un fouet frappant le sol, utilisée de manière ironique par Eugénie pour marquer la forte impression que devrait lui faire les paroles de Mathilde.

12. Onomatopée d'une moue de mépris qui exerce une succion sonore à l'intérieur de la bouche et crispe la bouche.

13. Mathilde tu m'énerves si tu ne te tais pas un peu je ne continuerai pas.

14. Mon dieu, quel phénomène (cette petite).

15. Allez ma petite ne te mets pas dans cet état.

16. Enfant d'une esclave faite Libre.

17. Depuis des temps immémoriaux.

18. Terme par lequel on désignait les Noirs ayant fait leurs humanités (Lettres Classiques).

19. Rivière de la Basse Terre.

20. Écrevisses de rivière.

21. Le renard et le lapin: contes traditionnels racontés lors des veillées.

22. Acajou. 